\title{
Correction to: Multiple Myeloma
}

\section{Christoph Heuck and Niels Weinhold}

\section{Correction to:}

Christoph Heuck and Niels Weinhold (eds.), Multiple Myeloma: Methods and Protocols, Methods in Molecular Biology, vol. 1792, https://doi.org/10.1007/978-1-4939-7865-6

In Chapter 4, the author's name Homer Adams III has been modified to Adams HC $3^{\text {rd }}$, as requested by him.

In Chapter 13 (page no. 186), the text in bold font in the below sentence has been revised to the following.

Section: 3.8 (Bisulfite Conversion)

2. Meanwhile, prepare the bisulfite conversion (CT) reagent by mixing $210 \mu \mathrm{L}$ of ultrapure water and $750 \mu \mathrm{L}$ of $\mathrm{M}$-dilution buffer to the content of CT-reagents per vial (see Note 7).

Has been replaced with

2. Meanwhile, prepare the bisulfite conversion (CT) reagent by mixing $210 \mu \mathrm{L}$ of Mdilution buffer and $750 \mu \mathrm{L}$ of ultrapure water to the content of CT-reagents per vial (see Note 7). 